\title{
Fostering Student Activism: Barriers, Sharing, and Dialectics
}

\author{
M. Candace Christensen ${ }^{1 *} \&$ Alexis V. Arczynski ${ }^{2}$ \\ ${ }^{1}$ University of Texas San Antonio, San Antonio, TX, USA \\ ${ }^{2}$ University of Utah, Salt Lake City, UT, USA \\ *M. Candace Christensen, E-mail: candace.christensen@utsa.edu
}

\begin{abstract}
The present study was an exploratory investigation of interviews with six college students who participated in the development and implementation of a theatre-based sexual assault prevention intervention. We investigated how these students experienced their involvement in activism within the context of developing and presenting a sexual assault prevention program. The research revealed common themes: each student experienced fears about participating in activism or identifying as an activist, had strong desires to share knowledge about sexual assault prevention with their community, and viewed their individual activist identities within a complex understanding of what it meant to be activists. These themes helped us to develop implications for future research and educational practices to support activist identity development.
\end{abstract}

\section{Keywords}

activism, feminist research, grounded theory, college students, barriers, motivation, activist identity development

\section{Introduction}

Encouraging students to value activism and engage in activist behaviors is in alignment with feminist praxis (Brown, 1994; Hooks, 1994; Tong, 2007). As feminist educators and scholars, we urge ourselves to not only counsel and educate, but to inspire our clients and students to develop a critical consciousness about how cultural norms, social systems, and interpersonal interactions support hegemonic practices that stratify us based upon our social locations (Friere, 1970; Hooks, 1994; Lorde, 1984; Tong, 2007). Beyond this critical consciousness, feminists urge individuals to use their awareness to change oppressive norms, systems, and interactions. As scholars, one of the communities with which we work is the college student population. As feminist scholars, we are committed to teaching our students how to analyze their individual, lived experiences from a lens that identifies power; intersections between race, class, and gender; and the value of equity. If we want our students to become change agents, we need to understand how they perceive the process of activism.

We begin with an overview of related scholarship. Then, we describe the sexual assault program from which participants were recruited, the participant recruitment procedures, the interview process, and the data analysis procedures. The heart of the article consists of the results of a qualitative investigation of 
how the students in this study understood, expressed, and identified activism and as activists.

Participating in activism can be a challenging endeavor, because it requires individuals to overcome internal and external barriers. Paulsen (1994) found that young adults with limited financial or social class resources were less likely to engage in social change involvement. Researchers found that participants distanced themselves from activism, because they believed the status quo to be satisfactory (Curry-Stevens, Lee, Datta, Hill, \& Edwards, 2008; Morton, Postmas, Haslam, \& Hornsey, 2009), desired to protect privileges borne out of inequity (Morton et al., 2009), or were oblivious to the existence of social injustice and inequity (Curry-Stevens et al., 2008; Gifford, 2011). Curry-Stevens and colleagues (2008) found that woman-identified participants expressed that their voices had been silenced due to patriarchy, white supremacy, nationalism, and classism; because they feared that others might resent their opposition to the status quo and harm them.

Further, a range of studies substantiated diverse factors that mediated internal and external barriers to activism. Prior research found that interpersonal relationships inspired involvement in activism via modeling of activist behaviors (Curry-Stevens et al, 2008; Pancer, Pratt, Hunsberger, \& Alisat, 2007), recruiting new participants, providing logistical information about how to get involved (Swank, 2012), developing relationships (Van Dyke \& Dixon, 2013), and creating safe communities (Linder \& Rodriguez, 2012). Researchers found that a sense of responsibility to create equity served to motivate activist behaviors (Curry-Stevens et al, 2008; Faver, 2001; Linder \& Rodriguez, 2012; Swank, 2012). Further, developing knowledge about social issues and enhancing activist skills inspired students' continued engagement in activism (Curry-Stevens et al., 2008; Pancer et al., 2007).Researchers discovered that prior involvement in activism forged greater empowerment (Van Dyke \& Dixson, 2013), subjective vitality (Klar \& Klasser, 2009), and motivation to continue to participate in activism (Pancer et al., 2007).

In addition, a person's identity statues may incite activism in nuanced ways. Linder and Rodriguez (2012) found that women of color college students were moved to action due to experiencing marginalization within their activist groups and in their broader college campuses. Further, research by Valocchi (2013) suggested that participants experienced their involvement in activism differently depending on their social class. For example, lower-class participants expressed that activism was a "way of life," working-class activists described activism as "a calling," while middle-class activists defined activism as "a career" (p. 180).

Identifying as an activist is tricky business: it requires a person to reflect on her or his values, determine which values are most important, and dedicate time and energy to creating social change that reflects those values (Komives, Owen, Longerbeam, Mainella, \& Osteen, 2005). Bashier, Lockwood, Chasteen, Nadolyny, and Noyes (2013) found that undergraduate participants and general public participants related activists with negative stereotypes (e.g., hostility, militancy, eccentricity); avoided associating with activists; and limited involvement in pro-change activities. Bobel (2007) found that participants perceived themselves to unable to live up to the activist "perfect standard" (e.g., all-seeing, 
unremitting, self-sacrificing, unflinching commitment, doing large-scale activism). Further, she found that participants distanced themselves from the arrogance they perceived in individuals who claimed an activist title.

The purpose of this exploratory study was to understand how a specific group of six college students understood the experience of activism. Our research questions were as follows: (a) How did students that participated in the development and implementation of a theatre-based sexual assault prevention program describe and experience the activism? (b) How did these students integrate their understanding of activism into their identities? To answer these questions, we utilized grounded theory coding procedures (Charmaz, 2006) to inductively discover themes that described the experiences of six college students that participated in the development and implementation of a theatre-based sexual assault prevention intervention at a large state university in the western United States (Christensen, 2013a, 2013c).

\section{Methods}

We chose qualitative methods as tools to achieve the goals of this study. Qualitative methods allowed for a sensitive, nuanced exploration of the topic, which allowed us to illuminate college students' subjective, individual expressions of activism (Charmaz, 2006; Hesse-Biber \& Leavy, 2011). A critical theory paradigm informed this study by focusing on the subjective and multiple truths of individuals and understanding that those realities were mediated by a power-laden context, which fostered the will of researchers and participants toward social action and emancipation (Hesse-Biber \& Leavy, 2011; Ponterotto, 2005). Thus, gathering and analyzing participants' experiences required an in-depth, systematic process for meaning making.

\subsection{Program Description}

The program in which the students participated was a theatre-based sexual assault prevention program created for a large state university in the southwest region of United States (Christensen, 2013a, 2013c). The development and implementation of this project was based on Rohd's Theatre for Community Conflict and Dialogue (1998). College students volunteered to collaboratively create and present a prevention program to their peers. The prevention program consisted of three co-created three to five minute scenarios highlighting the role of rape culture on a college campus. For the presentation, a peer facilitator introduced the presentation, led a discussion of the scenarios, encouraged audience members to join the performers to improvise solutions, and summarized the learning points that occurred because of the discussion and audience participation. The students collaboratively created and presented the prevention intervention as an interactive, improvisation-based, discussion-oriented program. Six of the eight active student members participated in the present study.

\subsection{Participants}

We used non-probability purposeful criterion sampling procedures to recruit participants who could provide rich information (Patton, 1990). Therefore, we sampled persons who actively attended group 
meetings and could provide maximum demographic variation. Participants for this study were six members of a peer education group at a large state university located in the southwestern United States. Member demographics included two men, four women, ages ranged from 19 to 29 years, five students, one recent graduate, two persons of color, four White individuals, one self-identified lesbian, and five self-identified heterosexuals. Because of the bounded focus of the study, the homogeneity of the participants, the demographic variation of participants, the use of grounded theory analysis, and the incorporation of multiple sources of data, the sample size of this study was appropriate (Sandelowski, 1995).

\subsection{Reflexivity}

We examined and owned our subjective experiences as researchers and participants, while adequately expressing participants' meanings. Thus, we engaged in a reflexive process to unearth where our experiences converged and diverged from participants' experiences (Morrow, 2005; Hesse-Biber \& Leavy, 2011). This reflexive process allowed us to present results that reflected the participants' experiences of participating in activism, versus our own.

\subsection{Researchers' Roles and Responsibilities}

As primary author, Candace acted as both as a participant observer in the research process for the present study (Morrow \& Smith, 2000). Thus, Candace participated in the development of the prevention program, but she also analyzed the experiences of students participating in that program. During data collection and development of the intervention, Candace utilized feminist ethics (Feminist, 1999) as a model for discussing how her roles as primary investigator and participant observer related to and diverged from the roles of participants. Initially, Alexis acted only as a participant in the study. Three years after the data collection, Alexis agreed to participate in the data analysis and writing of the manuscript. As an insider in the process of developing and presenting the intervention, Alexis, was able to infuse the data analysis with the credibility and authenticity that emerged from her insider perspective. Thus, we analyzed the data as colleagues, but we remained aware of our roles during the data collection: Candace was the researcher and Alexis was the researched. As we analyzed the data, we discussed our shifting roles, responsibilities, power dynamics, and relationship to one another as well as to the participants.

\subsubsection{Alexis}

As a participant in Candace's original study, I felt unsteady in my role as an activist and feared that I was not "enough" for the title. Working with a team of activists forced me to integrate the role of activist into my professional identity. As a result, I am an activist wherever I go and cannot envision my career without activism taking center stage. Further, as a co-researcher on this project, I have deepened and refined my understanding of activism. By reaching back in time to when my team members and I commenced our activism journeys, I reflected on my experiences not only to manage my subjectivity when analyzing the words of my peers, but also to understand the process of coming to know myself as an activist. Thus, being a participant and a researcher has required me to trace my path as an activist 
and to examine how my path was and is similar and different when compared to my participant peers.

\subsubsection{Candace}

Analyzing this data and writing the manuscript has forced me to be reflexive about whom I am as an activist. Like many of the participants of this project, I struggled with fear and confusion about what it meant to be an activist and about whether or not it was safe to claim that identity. Engaging Alexis in this research process added a layer of understanding and richness to the findings by providing me with many keen observations about how this process affected her identification as an activist. Infusing the data analysis with Alexis's point of view has thickened our findings to include a participant's perspective, which honors her unique experience as both a participant and a researcher.

\subsection{Recruitment}

Recruitment was accomplished through multiple methods. Candace, sent an email flyer to specific students who expressed interest in being part of the prevention program, three university resource center listservs, and gatekeepers in the field. The flyer specified the purpose of the project, information about the project and study, and an invitation to attend an orientation. At the orientation, Candace distributed two copies of informed consent forms, read through the form with the group, obtained signed forms from individuals interested in participating in the project, and asked interested persons to keep a copy for reference. The Institutional Review Board at the investigators' home university approved this study.

\subsection{Sources of Data}

We utilized grounded theory research methods to collect the data (Charmaz, 2006). Candace conducted six in-depth, semi-structured interviews as part of a previous study (Christensen, 2013c). Portions of the interviews focused on participants' experiences in the activist group, prior history with activism, and understanding of their activist identities. The in-depth, information-rich qualitative data provided significant insight into how the students experienced the activism within the context of developing and presenting the sexual assault prevention program. We included field notes written by Candace, reflexive evaluations written by each participant, and follow-up interview material. Sample interview questions were as follows:

(1) Can you tell me about your identity as an activist?

(2) What is activist work?

(3) How do you think the student group has inspired you to be an activist?

\subsection{Data Analysis}

We, Alexis and Candace, used grounded theory coding techniques as described by Charmaz (2006) to analyze this data. We began by immersing ourselves in the data by listening to the audio-recorded interviews, reading interview transcripts, and reading the written evaluations twice. We used open and focused coding techniques as described by Charmaz (2006). Open coding consisted of line-by-line analysis of the data resulting in a literal summarization of the data using key words verbalized by the interviewee/writer. By utilizing the constant comparative method of comparing data to data, data to 
codes, and codes to data, we engaged in focused coding, or developing themes in the data. Throughout the data collection and analysis process, we used analytic memos to explicate the analysis process by notating comparisons in the data, codes, and themes; to document the developing grounded description; and to write about changes in codes and themes.

\section{Results}

The purpose of this study was to explore how six college students experienced activism within the context of developing and presenting a theatre-based sexual assault prevention program. Using Charmaz's (2006) grounded theory coding techniques, we developed three major themes: Stifling Activist Behavior and Identity, Sharing Knowledge to Contribute to Communities, and Dialectics of an Activist Identity. We used the participants' own words to explain the main themes of the analysis.

\subsection{Stifling Activist Behavior and Identity}

We asked each participant to describe their identities as activists and how they defined activism. As a result, all of the participants told of internal and external barriers that stymied their comfort in identifying as activists and led them to undercut their current efforts. Generally, participants shared that fear was a major barrier for them. Being an activist was frightening for two central reasons. First, participants described fear of being targeted or misunderstood. Second, they discussed concerns about being able to measure up to the idealized, stereotyped, objectified activist. Although, specific barriers were varied, all participants shared that fear stifled their sense agency to participate in activist behaviors or to identify as activists. This stifling nature of fear caused them to downplay their efforts, kept them from acting, and/or silenced their identification as activists.

Individualized fears of not measuring up depended on participants' multiple, intersecting identities and lived experiences. Robert (19-year-old, undergraduate student, heterosexual, Latino man), like other participants, feared being misunderstood or hurt if he challenged other men.

I don't know if I'm very successful at all, because it's like you try to talk and they just shut down. I think I need to learn to be more tactful. It's more like you have to tiptoe around it. A little snippet here. A little snippet there. At first I wanted to have a direct conversation and with that not working. I think you can't really do that, you can't really direct conversation.

Robert's account emphasized the difficulty he faced in classifying himself as an activist or his behavior as activism, because he felt he was ineffectual in challenging his peers. He wished to have more information with which to confront others in his life and feared being misunderstood by his friends. He did not want to cause distance in his relationships with other men.

The following quote is from Eric (19-year-old, undergraduate student, heterosexual, White man). He easily identified himself as an activist and described his participation in the student group as activism. However, he described moments in which he silenced himself instead of speaking up against others because he struggled to obliterate perfectly the impact of hegemonic masculinity, sexism, heterosexism, 
and objectification in his socialization as a man.

I feel like I know what's right, but it's not always easy to do that. So, you're hanging out with the guys. You're watching TV. You see a "hot girl," as guys would say. And someone says, "Wow, she has a great rack," or "She has nice tits," or something like that. Sometimes I even find myself saying similar things. And, going to [the student group] makes me think, “Oh, maybe I shouldn't say that, and this is why. And, maybe when other people say those kinds of things, I should intervene." But most importantly, it's just changing yourself to not saying those things. Because in order to be able to tell other people "Don't say these things," you yourself have to not say them or else it's completely ineffective.

Eric's account emphasized the difficulty he felt to act out his activist values by challenging others' sexism because of his own mistakes. He referred to being immersed in the mundane and routine aspects of rape culture in his relationships with other men. Eric experienced cognitive dissonance after he engaged in sexist and objectifying behavior and later desired to challenge others' objectification of women. He appeared to be afraid to be a hypocrite or to feel guilt and shame for his own complicity in rape culture. His fear appeared to undercut his efforts to speak out and challenge his peers, left him feeling as though he did not measure up to other activists, and suggested that activists never act out on internalized oppression.

Alexis's (27-year-old, graduate student, lesbian, White woman) account captured other participants' difficulty in acknowledging micro-level actions as activism and their fears in taking on macro-level activism. For Alexis, her efforts in the counseling room were not enough and lesser to that of the work she did in revolution as an actor in performances for social change. Further, she captured the fear some activists with marginalized identities might experience due to the potential of being targeted, harassed, or harmed by people who felt threatened by activism.

People would say things like, "It is social justice work to work with your clients, empower your clients, help them to grow, and send them out into the world for them to do social justice," and it's really quite easy to do that instead of actually doing it. I think that my identity as a social justice activist is way newer and still scary. I haven't done a lot in that realm. Now, I want allies when I do it, so that I'm not doing it alone, cuz it scares the bejesus out of me. It's different when it's in the comfort of a classroom, or in the comfort of a client space versus having it be lots of people. I mean the things that I would be engaged in social activism for, violence against women, being an ally in anti-racism, sexual minorities, all those leave me as a target. That's kind of scary, and it's easy to say, "No. I don't want to do that." Now, I feel like that's a copout. (laughing)

Alexis made an assumption in her quote that in order to call herself an activist, she had to go beyond promoting social justice in her work with clients. She felt she had to go out into the community and encourage macro-level change in order to identify as an activist. Alexis referred to "hiding in her 
office," thereby suggesting that doing individual or group therapy was taking the easy road and therefore justified her not valuing her past work with countless clients. Further, she feared in being harmed in the process of engaging in public activism. She needed time to build a sense of safety and to build a community of support in order to engage in community-wide demonstrations of activism.

Participants evidenced similar emotional, cognitive, and relational processes underlying internal and external barriers to identifying their behavior and selves as activist behavior. Each participant felt stifled by the fears of not measuring up to stereotypical activism and the fears of being misunderstood or targeted for participating in activism. By doing so, participants downplayed micro forms of activism and emphasized the importance of doing versus being. Thus, their experience of cognitive dissonance when they made or feared making mistakes, by either mistakenly conveying what they learned about rape culture or acting out on internalized oppression, silenced them when they desired to challenge sexism. Further, their feelings of guilt because they did not do enough limited their ability to see their own efforts to make change.

\subsection{Sharing Knowledge to Contribute to Communities}

We asked participants to describe what motivated them to become part of the theatre-based sexual assault prevention program. All of the students mentioned a strong desire to share knowledge, to raise consciousness about the causes of sexual violence, and to prevent future sexual violence. Students described that the result of sharing knowledge and raising consciousness was making a significant contribution to their community. Participants also described how both internal and external forces influenced their motivation to take a stand on this topic. Internal forces that influenced students seemed to be an intrinsic desire to make a difference in their communities. External forces that influenced students appeared to be positive social pressure to demonstrate a commitment to preventing sexual violence in their community and a strong desire to be a role model for other students and community members.

In her feedback, completed after each student group meeting, Alexis (27-year-old, graduate student, White, Lesbian, woman), illustrated what it was like for her to witness group members learn how to raise awareness on the topic of sexual assault as a team:

I think it is compelling that people are not only actively participating in the group and learning about this stuff, but they are already willing to teach others - and so quickly! I think the process of raising awareness comes through a collaborative process with people sharing power with each other. At least that people in the group seem to have learned so much by being part of the experience of learning [from] and teaching [one another].

Alexis described what it was like for her to witness the growth of other group members (and possibly herself). She seemed inspired and motivated to contribute to the work this group was conducting, due to the commitment the other group members made to preventing sexual assault. Alexis drew attention to the group process: the values and skills the group members used to make decisions about how to construct the sexual assault prevention presentation. She implied that the process of developing the 
intervention was as important and instructive about how to engage in sexual assault prevention as the prevention presentation itself.

This quote is by Ashley (19-year-old, undergraduate student, White, heterosexual woman) was taken from the written feedback. Ashley self-reported having had less experience engaging in activism than other members of the group. In this quote, Ashley showed appreciation for how group members shared responsibility and collaborated both in developing and in presenting the intervention:

Everyone seems to have a part that fits him or her really well. I like all of the changes we made, and I thought we learned a lot about what we needed to say and how we needed to say it in order to conduct an effective presentation. Well, we had a very useful discussion about a particular rape myth that might be helpful when presenting to an audience.

Similar to Alexis, Ashley articulated an appreciation for the group process. She seemed to be inspired to participate and contribute to the prevention efforts of the group based upon how the other group members shared power within the intervention development meetings. She mentioned that the group had a good discussion, which implied that the result of the discussion made her feel included in the decision-making process and prepared to participate in a sexual assault prevention presentation with her peers. Additionally, implicit in this quote is a desire to give an "effective" presentation that would raise the consciousness of her peers about the problem of sexual violence and how to prevent it from occurring in her own community.

Maya (29-year-old, graduate student, heterosexual, Bicultural woman) expressed her motivation to engage in sexual assault prevention as an intrinsic desire to share her knowledge with students and inspire them to participate in sexual assault prevention:

It's not necessarily to be like, "I'm this high and mighty volunteer." But, to be like, "Anyone can do this. All you really need to do is get the training and be available to respond to this issue." If you want to make a change on this issue, you can do it, right? I try to encourage people to imagine a world where they can actually do something. I'm being a role model.

Maya discussed how she attempted to inspire other students to engage in activism. She talked about how to eliminate the psychological barriers many individuals had to engaging in activism, which was that it could be time and energy consuming. Maya portrayed activism as simple commitment that has the potential to change the world. She intimated that if we carried specialized knowledge and skills that had the potential to make the world a better place, we should be role models and actively influence our peers to take responsibility to create change.

These three students illuminated similar forms of inspiration for engaging in sexual assault prevention. All three students described a desire to share knowledge with their peers about sexual assault prevention in efforts to raise consciousness about how to solve the problem. They conveyed a strong sense of responsibility to take a stand on this issue and saw it as within their capacity to create positive social change in their communities. Alexis and Ashley described an external sense of motivation to 
create change based upon the level commitment and responsiveness they saw in the other group members. Maya implied that she felt an internal force to share her knowledge about sexual violence to raise consciousness and to influence her peers to be active on the issue.

\subsection{Dialectics of an Activist Identity}

We asked participant students to discuss how they identified as activists, and the responses we gathered ranged from not identifying as activists to identifying as having fully integrated activist identities. Within this range, we discovered common themes in the answers to this question, which seemed to encapsulate the common fiber of how each student interacted with this phenomenon. Students described their activist identity in three ways. First, they discussed how they learned to view activism from popular culture, including descriptions of seemingly stereotypical representations of activism or professional and moral obligations to be activists. Second, each student described his or her own activist identity or lack of activist identity. Two of the six students did not identify as activists which highlighted a dialectical tension between their esire to participate in sexual assault prevention but their reluctance to call oneself an activist. Finally, each student disclosed experiences they had in engaging in sexual assault prevention in interpersonal ways (through conversation) or on a larger scale (participating in a community awareness events). Although student responses to how they each identified as activists varied greatly, all six students seemed to dance between these three components.

Robert (19-years-old, undergraduate, heterosexual, Latino man) described how he viewed himself as an activist. He seemed unsure about how to define activism and as a result was not certain that he could identify as an activist.

I think they're more involved. I think I could be more involved than just going to meetings and trying to have discussions with my friends and stuff. I think they're doing more. I don't know exactly what more, but it'd be more. I think of someone on the front lines, like fighting a war almost, willing to lose everything for this thing, and going out there and dedicating themselves to that. I mean, I'm dedicated, but I don't know, it's an important issue. But, I would think an activist is more out there doing something.

Robert illuminated a tension he felt between his notions of how activism is performed and the work he did with sexual assault prevention. Robert acknowledged that he cared about sexual assault prevention and believed it was an important issue. However, he did not think he was doing enough or willing to give up enough in order to call himself an activist. Robert seemed to question the impact his efforts had in the prevention presentations and with his friends. Further, he consistently compared himself to a picture in which activists were fierce, passionate, and risked everything for a cause. He described conventional definitions, memes, or tropes based in mainstream United States culture. His quote implied that if one cannot behave like a true activist, then it is not worth engaging in activism, and one certainly cannot call oneself an activist.

In contrast to Robert, Katherine (26-year-old, recent graduate, heterosexual, White woman) delineated a confident understanding of activism, activist behavior, and her own activist identity. 
In my undergrad, I studied critical and cultural studies, social justice, and critical race theory. I really got into what I was learning about and interested through my major. I don't think at that point I would have called myself an activist. My peers seemed to be at a different level [than me]. They were all involved in ways I didn't feel like I could be. I always felt like I was very passionate about and interested in things but never felt like I could identify as an activist, because I wasn't doing activist work. Where I am at this point is I've been working with students, especially from under-represented and diverse populations. Also, being involved in groups like [student group], and I do some volunteering on the side that works specifically with high school girls. I like to consider myself an ally, and I find myself really trying to take on teaching moments when they are presented to me. I feel like I am doing those subtle activist type things. People make comments about a gender or racially grounded subject, and I find myself taking those on, and I feel obligated to address them, even if it's uncomfortable.

Katherine portrayed how she maneuvered between influences, activities, and her shifting identity. She recounted how her schooling inspired her to engage in activism, but she was not able to engage in activism until recently. Katherine defined activist behavior on multiple levels, she described her job as having an activist mission and her volunteer work as focusing on addressing sexual violence prevention and supporting young women. Katherine described tensions she experienced on the path to identifying as an activist, which were the dialectics between believing in activism and not behaving as an activist. However, through determination, she conceived of a path that aligned her activist values with her behavior

These two students depicted how they understood the phenomenon of activism and activist behaviors. This description included forces that inspired or motivated the students to value activism, behaviors they viewed as activist, and whether or not they identified as activists. Katherine had distinct definitions of activism, which seemed to have provided her with a clear understanding of how she might behave as an activist, and she unflinchingly identified as an activist. By contrast, Robert had an opaque understanding of activism and was reluctant to identify as an activist. Katherine seemed to successfully navigate the tension between stereotypical definitions of activism and her own identification with activism, whereas Robert was still developing an awareness of the connection between his values, behaviors, and willingness to identify as an activist.

\subsection{Summary}

We discovered three primary themes through the data analysis: Stifling Activist Behavior and Identity, Sharing Knowledge to Contribute to Communities, and Dialectics of an Activist Identity. All of the participants in this study articulated cognitive, emotional, and relational barriers to engaging in activism. Participants experienced a similar sense of being stifled based upon individual perceptions about activism: fear of not measuring up, fear of being misunderstood, or fear of being targeted for taking a stand on a given issue. These students expressed cognitive dissonance between an internal 
desire to challenge sexism and a fear that this activism will not create change or turn them into a target. In addition to barriers, all of the participants conveyed sources of inspiration for engaging in activism, including internal drives to share knowledge with others and external drives to be responsive, participating members of the student group. Both drives were located within participants' expressed moral obligation to share knowledge that could prevent sexual violence. Some students had a clear, salient understanding of activism and as a result did not hesitate to identify and behave as activists. Other students had a more muddled picture of the phenomenon and were hesitant to identify as activists or engage in activist behaviors. These findings revealed that the phenomenon of activism is far from an essentialized experience for college students.

\section{Discussion}

The purpose of this study was to understand how a particular group of university students understood and interacted with activism in the context of a sexual violence prevention program. Participants expressed internal and external barriers, which served to stifle their activist identification and behavior. They described personal and interpersonal inspirations that motivated their participation in activism. Participants described tensions between how activism aligned with participants' values, how participants understood the activism, and how they described their identification with an activist identity.

In line with previous research (Curry-Stevens et al., 2008; Morton et al., 2009), the participants in this study expressed that they feared being targeted by others who felt the status quo to be sufficient, which stifled their involvement in social change efforts. Further, the present findings substantiated prior research, because participants expressed fears that they did not measure up to the "perfect standard" of an activist (Bashier et al., 2013; Bobel, 2007). However, the results of this study diverged from prior research, because participants did not evidence a desire to distance from the stereotyped activist (Bashier et al., 2013), a sense of complacency with the status quo (Curry-Stevens et al., 2008; Gifford, 2011), or an unawareness of social justice or inequity (Morton et al., 2009). In part, this may be because the participants were already involved in social change. In addition, while the present research substantiated prior research that individuals defined the stereotyped "perfect" activist in similar ways, compared themselves to this ideology, and downplayed their activist behaviors (Bashier et al., 2013; Bobel, 2007), the present study expanded upon previous research by describing the tensions all participants experienced between definitional, behavioral, and identification phenomena.

The results of the present study substantiated the claims of prior research regarding students' internalized sense of moral responsibility to change their communities, to create equity by reducing sexual violence (Curry-Stevens et al, 2008; Faver, 2001; Linder \& Rodriguez, 2012; Swank, 2012), and a desire to build relationships and a safe community (Favor, 2001; Linder \& Rodriguez, 2012; Van Dyke \& Dixon, 2013). Further, participants evidenced a desire to continue being involved in social change in order to develop additional knowledge and skills, which substantiated prior research 
(Curry-Stevens et al., 2008; Pancer et al., 2007). The results of this study expanded prior research by emphasizing that participants desired to inspire outside observers to join their activist efforts.

\subsection{Limitations and Implications for Future Research}

This study has limitations that should be addressed in future research. We did not check our model with our participants, which would have improved the credibility our analysis. Alexis did not participate in the data collection process, which may have diminished power differentials between researchers and participants, shaped the interview questions to elicit credible information from the participants, and added an additional layer of understanding to the data analysis. The participants may have changed over the three-year time lapse between original data collection and data analysis; it might be worthwhile to conduct follow-up interviews with the participants to explore how they currently identify as activists. Given the size and homogeneity of the sample, future research could improve upon this study by interviewing a larger and more diverse sample of students. Future research may benefit from evaluating the effectiveness of interventions developed out of the results of this study in contributing to students' engagement in activism, identification as activists, personal benefits from engaging in activism, and community benefits from engaging in activism.

\subsection{Conclusion}

By giving themselves credit for the work they do students may inspire, influence, and recruit other students to engage in activism. It seems important that students have a clear understanding that the activist work they do is valuable and can be articulated as activism, as socially conscious, as responsive, as ethical, or as sharing knowledge and power. Thus, the findings from this study suggested that educators might assist students in participating in activism and identifying their own behaviors as activism through numerous interventions. Teaching students about activist stereotypes and activism myths may assist students in developing a more nuanced and complex understanding of how activism is embodied and performed in daily life. Finally, defining and illustrating micro-, mezzo-, and macro-level activist practices may help students participate in ways that fit their unique preferences and skills help students to see their own actions as activist.

Participants in this study shared similar fears or concerns about being misunderstood, targeted, or harmed by participating in activism. In part, this fear could be due to the stereotyped, objectified, unattractive portrayal of activists in popular culture (Bashier et al., 2013). In addition, their fears may be based in the realities of marginalized persons' lived experiences. Social justice communities may benefit from allowing for space wherein group members can explore fears of participating in social change efforts and identifying as activists. This may allow participants to face their fears, acknowledge where they come from, and develop solutions to their fears in the context of a group process replete with potential feedback and support.

For some participants, engaging in prevention efforts enhanced their ability to identify as activists and to maintain that identification. Building a collaborative, power-sharing process helped to facilitate participants' sense of agency to join sexual assault prevention efforts, to allow for participants to see 
others challenge themselves to grow, and to provide a conduit for having and being role models. Further, engaging students in self-reflexive, group-based dialogue about perceived barriers and motivations for engaging in activism may assist students in understanding and clarifying their inhibitions to engaging in activism and ways to move past inhibitions. Building social change communities that promoted power-sharing and allowed for collaboration may facilitate not only activist efforts but activist identification.

\section{References}

Bashir, N. Y., Lockwood, P., Chasteen, A. L., Nadolny, D., \& Noyes, I. (2013). The ironic impact of activists: Negative stereotypes reduce social change influence. European Journal of Social Psychology, 43, 614-626.

Bobel, C. (2007). "I'm not an activist, though I've done a lot of it": Doing Activism, Being Activist and the "Perfect Standard" in a Contemporary Movement. Social Movement Studies, 6(2), 147-159.

Brown, L. S. (2004). Subversive dialogues: Theory in feminist therapy. Basic Books.

Charmaz, K. (2006). Constructing grounded theory. London, U.K.: Sage.

Christensen, M. C. (2013a). Engaging theatre for social change to address violence against college women: A qualitative investigation. British Journal of Social Work.

Christensen, M. C. (2013b). Using feminist leadership to build a peer education program: A qualitative evaluation. Journal of Qualitative Social Work, 12(3), 254-269.

Christensen, M. C. (2013c). Using theatre of the oppressed to address sexual violence against women on college campuses. Trauma, Abuse, \& Violence, 14(4), 282-294.

Curry-Stevens, A., Lee, C., Datta, J., Hill, E., \& Edwards, V. (2008). Activist formation in the neoliberal era: A journey with multiple dimensions. Affilia, 23, 290-298.

Feminist Therapy Institute. (1999). Feminist Therapy Code of Ethics. Retrieved from http://www. feministtherapyinstitute.org/ethics.htm

Friere, P. (1970). Pedagogy of the oppressed. New York, NY: Continuum.

Hesse-Biber, S. N., \& Leavy, P. (2011). The practice of qualitative research. Thousand Oaks, CA: Sage.

Hooks, B. (1994). Teaching to transgress: Education as the practice to freedom. New York, NY: Routledge.

Klar, M., \& Kasser, T. (2009). Some benefits of being an activist: Measuring activism and its role in psychological well-being. Political Psychology, 30, 755-777.

Komives, S. R., Owen, J. E., Longerbeam, S. D., Mainella, F. C., \& Osteen, L. (2005). Developing a leadership identity: A grounded theory. Journal of College Student Development, 46, 593-611.

Linder, C., \& Rodriguez, K. (2012). Learning from the Experiences of Self-Identified Women of Color Activists. Journal of College Student Development, 53, 383-398.

Lorde, A. (1984). Age, race, class, and sex: Women redefining difference. In Sister Outsiders: The representation of identity and difference (pp. 114-123). Trumansburg, NY: Crossing Press.

Published by SCHOLINK INC 
Marshall, C., \& Rossman, G. B. (2011). Designing qualitative research. Thousand Oaks, CA: Sage.

Morrow, S. L. (2005). Quality and trustworthiness in qualitative research in counseling psychology. Journal of Counseling Psychology, 52, 250-260.

Morrow, S. L., \& Smith, L. M. (2000). Qualitative research for counseling psychology. In S. D. Brown, \& R. W. Lent (Eds.), Handbook of Counseling Psychology (3rd ed., pp. 119-230). New York, NY: Wiley.

Morton, T. A., Postmes, T., Haslam, S., \& Hornsey, M. J. (2009). Theorizing gender in the face of social change: Is there anything essential about essentialism? Journal of Personality And Social Psychology, 96(3), 653-664.

Pancer, S. M., Pratt, M., Husberger, B., \& Alisat, S. (2007). Community and political involvement in adolescence: What distinguishes the activists from the uninvolved? Journal of Community Psychology, 35, 741-759.

Patton, M. P. (1990). Qualitative evaluation and research methods. Thousand Oaks, CA: Sage.

Paulsen, R. (1994). Status and action: How stratification affects the protest participation of young adults. Sociological Perspectives, 37(4), 635-649.

Ponterotto, J. G. (2005). Qualitative research in counseling psychology: A primer on research paradigms and philosophy of science. Journal of Counseling Psychology, 52, 126-136.

Sandelowski, M. (1995). Qualitative analysis: What it is and how to begin. Research in Nursing and Health, 18, 371-375.

Swank, E. W. (2012). Predictors of political activism among social work students. Journal of Social Work Education, 48(2), 245-266.

Tong, R. (2007). Feminist thought in transition: Never a dull moment. The Social Science Journal, 44, 23-39.

Valocchi, S. (2013). Activism as a career, calling, and way of life. Journal of Contemporary Ethnography, 42, 169-200.

Van Dyke, N., \& Dixon, M. (2013). Activist human capital: Skills acquisition and the development of commitment to social movement activism. Mobilization: An International Journal, 18, 197-212. 